\title{
Using Market Segmentation Analysis to Identify Consumer Preferences for Fresh Peach Attributes
}

\author{
Ruchen Zhou \\ Department of Applied Economics, University of Minnesota-Twin Cities, \\ Minneapolis, MN 55455
}

Chengyan Yue

Departments of Applied Economics and Horticultural Science, Bachman Endowed Chair in Horticultural Marketing, University of Minnesota-Twin Cities, Minneapolis, MN 55455

\author{
Shuoli Zhao \\ Department of Applied Economics, University of Minnesota-Twin Cities, \\ Minneapolis, MN 55455
}

\section{R. Karina Gallardo and Vicki McCracken \\ School of Economics, Washington State University, Pullman, WA 99163}

James J. Luby

Department of Horticultural Science, University of Minnesota-Twin Cities, Minneapolis, MN 55455

\section{James R. McFerson ${ }^{1}$ \\ Washington Tree Fruit Research Commission, Wenatchee, WA 98801}

Additional index words. fresh peaches, consumer preference, consumer segmentation, latent class model, fruit retailers

\begin{abstract}
Consumer preferences for attributes of fresh peach fruit in the United States are largely unknown on a national basis. We used a choice experiment to explore market segmentation based on consumer heterogeneous preference for fruit attributes including external color, blemish, firmness, sweetness, flavor, and price. We collected the data using an online survey with 800 U.S. consumers. Using a latent class logit model, we identified three segments of consumers differing by different sets of preferred quality attributes: experience attribute-oriented consumers, who valued fruit quality $(\mathbf{4 8 . 8 \%}$ of the sample); search attribute-oriented consumers, who valued fruit appearance $(33.7 \%$ of the sample); and balanced consumers, who considered search attributes and experience attributes but who valued each in a balanced way (17.5\% of the sample). Each group demonstrated differentiated demographics and purchasing habits. The results have important marketing implications for peach breeders and suppliers.
\end{abstract}

In 2016, United States ranked the fourth peach-producing country in the world, with a total production of 927,178 tons, following China, Spain, and Italy (Food and Agricultural Organization of the United Nations, 2018). Total U.S. peach exports were $\$ 200$ million in 2012, \$173.4 million of which were fresh market fruit, whereas total imports were $\$ 161.3$ in 2012, \$50.3 million of which

Received for publication 30 Apr. 2018. Accepted for publication 20 June 2018.

This research was funded by the USDA National Institute of Food and Agriculture Specialty Crop Research Initiative projects "RosBREED: Enabling marker-assisted breeding in Rosaceae" (2009-51181-05808) and "RosBREED: Combining Disease Resistance with Horticultural Quality" (2014-51181-22378).

${ }^{1}$ Director.

${ }^{2}$ Corresponding author. E-mail: yuechy@umn.edu. were fresh market fruit (Economic Research Service, U.S. Department of Agriculture, 2015). Despite ongoing marketing efforts from the public and private sectors, overall per-capita consumption of fruit in the United States is less than half of the recommended amount. Fresh market peach exemplifies this unfortunate trend, despite ranking seventh among fruits in per capita consumption in the United States. Even with an average retail price that has remained steady since the 2000 s, domestic consumption of fresh peaches has steadily decreased from around 6 pounds in the $1980 \mathrm{~s}$, to around 5 pounds in 2008, and to less than 3 pounds in 2016. Concurrently, the bearing acreage of peach trees has declined from around 190,000 acres in the 1980s to roughly 94,100 acres in 2016 (Economic Research Service, U.S. Department of Agriculture, 2017).

Unlike fruits such as oranges or apples, fresh peaches have a short shelf life and a narrow harvest window. Peach fruit require gentle handling and strict storage conditions, making quality consistency difficult to achieve; furthermore, consumers at the point of sale often are unable to identify properly handled peach fruit (Uva et al., 2004). Mediocre and/or inconsistent quality might prevent consumers from purchasing fresh peaches regularly. Understanding consumer preferences for peach fruit quality attributes could provide critical information to the U.S. peach industry to effectively marketing their products.

A number of studies have assessed consumer preferences for specific fruit attributes. For example, van der Pol and Ryan (1996) found Scottish consumers preferred fruits that were sold in supermarkets and loosely packaged, as well as with greater quality and lower price. Loureiro et al. (2001) studied Oregon consumer choices among conventional apples, apples with eco-labels, and organic apples. They found consumers considered eco-labeled apples a transitional option between relatively unfavorable conventional apples and favorable organic apples. Crisosto et al. (2003) found that Californian consumers preferred fresh sweet cherry fruits with higher soluble solid concentration and dark color and that older consumers have a stronger preference for these two attributes. Campbell et al. (2004) conducted an analysis on Alabama and Georgia consumer preferences for Satsuma oranges. They found three groups of consumers defined by their preferences for fewer blemishes, lower price, and fewer seeds, respectively, and the three groups differed in their demographics such as gender, ethnicity, age, and family structure.

In a study focused on fresh market peach fruit quality attributes, Bruhn (1995) interviewed consumers in grocery stores in Boston, Atlanta, Chicago, Los Angeles, and Northern California and concluded the most important attributes used to determine the quality of peach fruit were firmness, color, and aroma. In addition, consumers saw smaller size as an indicator of poor quality.

Uva and Cheng (2005) conducted a survey with randomly chosen household samples in New York State to quantify how each peach fruit attribute affected consumer-purchasing decisions, finding the probability of paying a premium for tree-ripened peaches increased with consumers' previous purchasing experience and decreased with dissatisfaction with the tree-ripened peaches previously consumed.

Two studies in Germany and Canada investigated preference heterogeneity among peach consumers and attempted to divide consumers into groups based on the heterogeneity. Cembalo et al. (2009) used a choice experiment to study German consumers' attitudes toward the country of origin for peaches traded in the European Union. They identified three segments differentiated by preferences for the country of origin and price sensitivity. Each of the three segments preferred peaches from Italy, Spain, and Turkey and demonstrated an increasing sensitivity to price. Campbell et al. (2013) conducted a national survey of Canadian consumers about their preferences for Ontario-grown peaches, and 
they grouped the consumers into six clusters based on similarity of preferences. The six clusters were primarily driven by low price, labels of one or more specific regions in Canada, red external color, large size, and firm peaches. The study further described each cluster by factors such as consumers' gender, age, education, income, living areas, shopping places and knowledge of local produce.

These previous studies have contributed to the understanding of foreign or regionspecific U.S. consumers' preferences for fresh market peach. Yet, preference heterogeneity among U.S. consumers at a national level is still largely unknown. In this study, we aimed to explore U.S. consumer preferences for fresh market peaches, identify possible segments within this market, quantify the characteristics of these consumer segments, and draw marketing implications based on the segmentation results.

\section{Methodology}

Data. We collected the data using an online survey by Qualtrics (Provo, UT and Seattle, WA), a professional survey company. We screened participants based on their response to the prescreening question: "Have you purchased fresh peaches in the past year?" Only consumers who answered "Yes" were allowed to proceed with the survey.

The survey had two sections - one section included choice scenarios representing peaches with different combinations of quality attributes, and the second section contained questions concerning respondents' socioeconomic and demographics, purchasing habits, and opinions about fresh peaches. Six quality attributes with two levels for each were included in the choice scenarios, selected on the basis of previous literature and consultations with industry experts. Table 1 summarizes the quality attributes: external color, exterior blemishes, size, firmness, sweetness, and flavor. We also included price as another attribute. The price levels, \$2.19/ $\mathrm{lb}$ and $\$ 1.69 / \mathrm{lb}$, were based on the retail price of peaches in different types of stores. It was not practical to ask participants to evaluate all the $128\left(2^{7}\right)$ combinations of the attributes. We employed a fractional factorial design using JMP8 software (SAS Institute, Cary,

Table 1. Attribute levels for choice experiment questions used in the U.S. peach consumer survey (sample size: 800).

\begin{tabular}{|c|c|}
\hline Attributes & Level \\
\hline \multirow[t]{2}{*}{ External color } & Red \\
\hline & Yellow \\
\hline \multirow{2}{*}{ External blemishes } & More defects on the surface \\
\hline & Less defects on the surface \\
\hline \multirow[t]{2}{*}{ Size } & More than 2.75-inch diameter \\
\hline & Less than 2.75-inch diameter \\
\hline \multirow[t]{2}{*}{ Firmness } & Firm \\
\hline & Soft \\
\hline \multirow[t]{2}{*}{ Sweetness } & High \\
\hline & Low \\
\hline \multirow[t]{2}{*}{ Flavor } & Intense peach flavor \\
\hline & Mild peach flavor \\
\hline \multirow[t]{2}{*}{ Price } & $\$ 2.19 / 1 \mathrm{~b}$ \\
\hline & $\$ 1.69 / \mathrm{lb}$ \\
\hline
\end{tabular}

NC) to reduce the number of product profiles, and each participant was asked to evaluate 16 profiles in eight separate choice scenarios.

Each choice scenario had two product profiles labeled as "Option A" and "Option B." Options A and B were represented by different combinations of the quality attributes. Exterior blemishes and external color were presented in photos and the other attributes were described in text. If participants did not like Option A or Option B, they could choose the third option: "Neither A or B." We included "Neither A or B" to avoid forced choice, and hence to avoid overestimating the possibility that an available option was chosen (Kontoleon and Yabe, 2003).

Econometric model. We employed a latent class logit model to investigate consumer preference heterogeneity. The latent class model assumed that participants can be classified into $S$ segments that were unobservable. People in the same segment were homogenous in tastes and had similar underlying preferences. Compared with other commonly used models with consumer data such as the standard logit or mixed logit, the latent class logit model did not restrict the number of classes and allowed preferences to vary randomly in the population. Moreover, the latent class logit model was able to identify the sources of preference heterogeneity, shown in the choice probability as

$$
L_{n j}=\sum_{s=1}^{S} M_{s}\left(\frac{\exp \left(\alpha_{s} X_{n j}\right)}{\sum_{k \in J} \exp \left(\alpha_{s} X_{n k}\right)}\right)
$$

where $\alpha_{s}$ was class s' coefficients for peach attributes $X_{n j}$. $M_{s}$ was the membership likelihood function, which determines the class with which an individual $n$ is affiliated, based on his or her characteristics. This membership function was represented as

$$
M_{s}=\frac{\exp \left(\lambda_{s} Z_{n}\right)}{\sum_{s=1}^{s} \exp \left(\lambda_{s} Z_{n}\right)}
$$

where $Z_{n}$ was a vector of individual characteristics, and $\lambda_{s}$ was a vector of parameters. Combining (1) and (2), the choice probability of individual $n$ for attribute $j$, conditional on being a member of class $\mathrm{s}$ was expressed as

$$
\begin{array}{r}
L_{n j}=\sum_{S=1}^{S}\left[\frac{\exp \left(\lambda_{s} Z_{n}\right)}{\sum_{s=1}^{s} \exp \left(\lambda_{s} Z_{n}\right)}\right] \\
\\
{\left[\frac{\exp \left(\alpha_{s} X_{n j}\right)}{\sum_{k \in J} \exp \left(\alpha_{s} X_{n k}\right)}\right]}
\end{array}
$$

The latent class logit model estimated $\alpha_{s}$ and $\lambda_{s}$ simultaneously via maximum likelihood methods. To identify the $\lambda_{s}$ vectors, one of the segment's $\lambda_{s}$ vector must be normalized to zero (Boxall and Adamowicz, 2002). In the application here, the attributes of fresh market peach fruit for choice set $j$ were included in vector $X_{n j}$, and the sociodemographic information and purchasing habits of individuals were included in vector $Z_{n}$.

\section{Results}

In total, 800 of participants completed the choice experiments and the questionnaire and generated usable results. The summary statistics of participants are shown in Table 2 . Participants had an average age of 42 years and were categorized as Boomers (born before 1964), Gen X (born between 1965 and 1980), and Gen Y (born after 1980). The proportions of Boomers, Gen X, and Gen Y in this sample were $28 \%, 35 \%$, and $37 \%$, respectively. The majority of participants were Caucasian $(79 \%)$, female $(63 \%)$, and more than $40 \%$ of the participants have at least one child younger than 12 years old. Seventy percent of the participants had at least a high school degree, and almost $40 \%$ had at least a 4-year college degree. Nearly one third $(33.25 \%)$ of the participants had an annual household income between $\$ 25,000$ and $\$ 49,999$, and $29 \%$ of them earned more than $\$ 75,000$. Participants, on average, purchased 4.9 fresh peaches at one time. More than half of the participants were frequent buyers, purchasing peaches at least once a week. Only a small proportion of the participants $(12.13 \%)$ were occasional buyers, purchasing peaches less than once a month. Overall, our sample was representative of the U.S. population in terms of age, race, and education. However, relative to the U.S. census, since we screened respondents based on their past peach purchase, our sample demographics contained more female participants (64\%) who were the major grocery shoppers, more medium-income households, and only those who had purchased peach in the previous year. Such deviation was common in consumer studies such as Adalja et al. (2015), Loureiro et al. (2001), and Dobbs et al. (2016).

As Eq. [3] suggests, the number of classes was unknown and needed to be estimated before individual coefficients were derived for the latent class logit model. To decide on the optimal number of class, we evaluated models ranging from two to eight classes and compared the goodness-of-fit of each model using the Akaike Information Criterion (AIC), the Bayesian Information Criterion (BIC), and the posterior probability. These statistics, along with log-likelihood estimates, are listed in Table 3. According to the statistics, the marginal increase of loglikelihood, AIC, and BIC achieved maximum when increasing the model specification from two-class to three-class. In addition, model estimations with four or more classes all contained at least one small class that was smaller than $10 \%$ in size. Another indicator was posterior prediction accuracy, and it quantified the accurate percentage of prediction, given the respondent was in a particular class based on his/her choice and demographic characteristics. In this case, the two-class and three-class models also had the greatest posterior prediction accuracy. Because the AIC and BIC had the largest reduction from two to three classes whereas posterior prediction accuracy only decreased $3 \%$, we decided to use three-class latent class logit model.

Table 4 shows the estimation results from the latent class logit model. To explore the demographic effect on class membership, we 
Table 2. Summary statistics of participants' demographic variables from a U.S. peach consumer survey (sample size: 800).

\begin{tabular}{|c|c|c|c|}
\hline Variables & Description & Mean/percent & SD \\
\hline Gen Y & Dummy variable: 1 if participant was born after $1980 ; 0$ otherwise & $37.38 \%$ & 0.484 \\
\hline Boomer & Dummy variable: 1 if participant was born between 1946 and 1964; 0 otherwise & $17.00 \%$ & 0.376 \\
\hline Male & Dummy variable: 1 if male; 0 if female & $36.75 \%$ & 0.482 \\
\hline Having children & Dummy variable: 1 if participant has children $<12$ years old in household; 0 otherwise & $43.38 \%$ & 0.496 \\
\hline Live alone & Dummy variable: 1 if participant lives in a one-person household: 0 otherwise & $13.75 \%$ & 0.344 \\
\hline South & Dummy variables: 1 if participant lives in the South; 0 otherwise & $36.25 \%$ & 0.481 \\
\hline Midwest & Dummy variable: 1 if participant lives in the Midwest; 0 otherwise & $26.00 \%$ & 0.439 \\
\hline \multicolumn{4}{|c|}{ - } \\
\hline High school & Dummy variable: 1 if participant's highest education is high school; 0 otherwise & $32.00 \%$ & 0.467 \\
\hline College & Dummy variable: 1 if participant's highest education is four-year college; 0 otherwise & $27.00 \%$ & 0.444 \\
\hline Graduate school & Dummy variable: 1 if participant's highest education is graduate school; 0 otherwise & $10.00 \%$ & 0.300 \\
\hline Higher income & Dummy variable: 1 if participant's annual household income is $>\$ 75,000 ; 0$ otherwise & $29.00 \%$ & 0.454 \\
\hline Number of peaches per purchase & Number of peaches purchased by participants & 4.879 & 1.541 \\
\hline Frequent buyer & Dummy variable: 1 if participant purchases peaches at least once a month; 0 otherwise & $54.88 \%$ & 0.498 \\
\hline Occasional buyer & Dummy variable: 1 if participant purchases peaches less than once a month; 0 otherwise & $12.13 \%$ & 0.326 \\
\hline
\end{tabular}

Table 3. Statistic comparison of goodness-of-fit from the estimations of latent class logit model with the specification of two to eight classes using the U.S. peach consumer survey (sample size: 800).

\begin{tabular}{lccrrr}
\hline Number of classes & Number of parameters & Log likelihood at convergence (LL) & AIC & BIC & Posterior prediction accuracy \\
\hline 2 & 17 & $-5,421.8603$ & $10,877.721$ & $10,957.359$ & 0.955 \\
3 & 26 & $-5,175.987$ & $10,403.973$ & $10,526.773$ & 0.925 \\
4 & 35 & $-5,104.577$ & $10,279.154$ & $10,443.116$ & 0.917 \\
5 & 44 & $-5,022.711$ & $10,133.420$ & $10,339.540$ & 0.880 \\
6 & 53 & $-4,987.213$ & $10,080.425$ & $10,328.710$ & 0.876 \\
7 & 62 & $-4,890.389$ & $9,904.778$ & $10,195.224$ & 0.875 \\
8 & 71 & $-4,835.766$ & $9,813.532$ & $10,146.140$ & 0.880 \\
\hline
\end{tabular}

$\mathrm{AIC}=$ Akaike Information Criterion; BIC $=$ the Bayesian Information Criterion.

included sociodemographic variables and purchasing habits in the membership function. Note that class 3's membership parameters were set to zero (normalization) for purposes of identification and the parameters of the other two groups were interpreted relative to this class. The results showed all three classes preferred peaches with a greater level of sweetness and fewer exterior defects. Despite these similarities, each class also exhibited unique patterns in preferences.

Class 1 accounted for $48.8 \%$ of the sample. This group's coefficient for sweetness was the greatest among the three classes, suggesting participants in class 1 were more likely to purchase peaches with a greater level of sweetness. In addition, class 1 preferred peaches with an intense flavor and fewer defects on the fruit surface. Lastly, participants in class 1 did not consider other aspects of appearances as important, such as external color and size, and, contrary to the other two classes, people in class 1 were sensitive to price.

Nelson $(1970,1974)$ and Darby and Karni (1973) classified product attributes of peaches into experience attributes and search attributes. Experience attributes were those attributes that consumers can verify only after consumption, such as sweetness and flavor. Search attributes were those attributes consumers can verify before purchase, such as color, size, firmness, and exterior defects. The consumer preferences of class 1 were clearly dominated by experience attributes, and thus this class was named "experience attribute-oriented consumers."

Class 3 was the next largest group, accounting for $33.7 \%$ of the sample, and was named "search attribute-oriented consumers." This group considered all search attributes as important: firmness, size, color, and external blemishes. Class 3 consumers preferred firmer, larger peaches with a reddish color and ones with fewer exterior defects. Their preferences of large and firm peaches were consistent with the external feeloriented groups identified in the study of Campbell et al. (2013) on Canadian consumers. Class 3 consumer preferences for experience attributes were far less pronounced than class 1 (experience attributeoriented consumers). The only experience attribute that was significant was sweetness, with a numerically small coefficient of 0.085 . In contrast to class 1 , search attribute-oriented consumers were more price sensitive. The price coefficient was the largest in magnitude compared with the other classes.
Class 2, the remaining $17.5 \%$ of the sample, reflected a combination of preferences of the experience attribute-oriented consumers and search attribute-oriented consumers. This group considered one experience attribute (sweetness) and one search attribute (external blemishes) as important and were price sensitive. However, the magnitude of the coefficients was not as large as for the other two classes, indicating that they were less sensitive to the levels of the attributes that they were confronted with in the choice scenarios. Thus, this class was named "balanced consumers."

A significant membership parameter shown in Table 4 suggested the variable of the corresponding class differed from that of the third class. Experience attribute-oriented consumers (class 1) were significantly different from search attribute-oriented consumers (class 3 ) in terms of gender, having children or not, the number of peaches bought per purchase (5\% significance level), and being an occasional or frequent buyer (10\% significance level). The experience attributeoriented consumers were less likely to have children and more likely to be female. From the perspective of purchasing habits, the experience attribute-oriented consumers purchased relatively more peaches at each 
Table 4. Latent class model estimation results of consumer segmentation using U.S. peach consumer survey data (sample size: 800 ).

\begin{tabular}{|c|c|c|c|}
\hline & Class 1: & Class 2: & Class 3: \\
\hline Variables & $\begin{array}{l}\overline{\text { Experience attribute-oriented }} \\
\text { consumers }\end{array}$ & $\begin{array}{l}\text { Balanced } \\
\text { consumers }\end{array}$ & $\begin{array}{c}\text { Search attribute-oriented } \\
\text { consumers }\end{array}$ \\
\hline External blemishes & $\begin{array}{l}-0.102^{* * *} \\
(0.031)\end{array}$ & $\begin{array}{l}-0.107^{* *} \\
(0.053)\end{array}$ & $\begin{array}{l}-0.191^{* * *} \\
(0.031)\end{array}$ \\
\hline External color & $\begin{array}{l}-0.047 \\
(0.044)\end{array}$ & $\begin{array}{c}-0.006 \\
(0.069)\end{array}$ & $\begin{array}{l}0.112 * * \\
(0.045)\end{array}$ \\
\hline Size & $\begin{array}{l}-0.142 \\
(0.112)\end{array}$ & $\begin{array}{c}0.118 \\
(0.089)\end{array}$ & $\begin{array}{l}0.279^{* * *} \\
(0.075)\end{array}$ \\
\hline Firmness & $\begin{array}{l}-0.144 * * * \\
(0.041)\end{array}$ & $\begin{array}{l}0.086 \\
(0.073)\end{array}$ & $\begin{array}{l}0.268^{* * *} \\
(0.041)\end{array}$ \\
\hline Sweetness & $\begin{array}{l}0.533^{* * * *} \\
(0.033)\end{array}$ & $\begin{array}{l}0.403 * * * \\
(0.070)\end{array}$ & $\begin{array}{l}0.084 * * \\
(0.036)\end{array}$ \\
\hline Flavor & $\begin{array}{l}0.391 * * * \\
(0.030)\end{array}$ & $\begin{array}{c}0.089 \\
(0.063)\end{array}$ & $\begin{array}{l}-0.053 \\
(0.033)\end{array}$ \\
\hline Price & $\begin{array}{c}0.659 \\
(0.480)\end{array}$ & $\begin{array}{l}-1.613 * * * \\
(0.499)\end{array}$ & $\begin{array}{l}-2.195^{* * *} \\
(0.374)\end{array}$ \\
\hline \multicolumn{4}{|l|}{ Age } \\
\hline Gen X & $\begin{array}{c}0.184 \\
(0.342)\end{array}$ & $\begin{array}{c}0.137 \\
(0.465)\end{array}$ & 0 \\
\hline Gen Y & $\begin{array}{l}-0.041 \\
(0.339)\end{array}$ & $\begin{array}{l}-0.079 \\
(0.466)\end{array}$ & 0 \\
\hline Boomer & $\begin{array}{l}-0.227 \\
(0.361)\end{array}$ & $\begin{array}{c}0.071 \\
(0.488)\end{array}$ & 0 \\
\hline Male & $\begin{array}{l}-0.380 * * \\
(0.193)\end{array}$ & $\begin{array}{l}-0.561^{* *} \\
(0.263)\end{array}$ & 0 \\
\hline Caucasian & $\begin{array}{c}0.328 \\
(0.243)\end{array}$ & $\begin{array}{l}-0.424 \\
(0.295)\end{array}$ & 0 \\
\hline Children & $\begin{array}{l}-0.498 * * \\
(0.212)\end{array}$ & $\begin{array}{c}-0.092 \\
(0.279)\end{array}$ & 0 \\
\hline \multicolumn{4}{|l|}{ Region } \\
\hline Midwest & $\begin{array}{c}0.021 \\
(0.360)\end{array}$ & $\begin{array}{c}0.020 \\
(0.471)\end{array}$ & 0 \\
\hline Northeast & $\begin{array}{l}-0.137 \\
(0.386)\end{array}$ & $\begin{array}{l}-0.175 \\
(0.498)\end{array}$ & 0 \\
\hline South & $\begin{array}{l}0.250 \\
(0.350)\end{array}$ & $\begin{array}{c}0.138 \\
(0.457)\end{array}$ & 0 \\
\hline West & $\begin{array}{c}-0.039 \\
(0.389)\end{array}$ & $\begin{array}{c}0.615 \\
(0.473)\end{array}$ & 0 \\
\hline \multicolumn{4}{|l|}{ Education } \\
\hline High school & $\begin{array}{l}-0.293 \\
(0.238)\end{array}$ & $\begin{array}{c}0.304 \\
(0.311)\end{array}$ & 0 \\
\hline College & $\begin{array}{l}-0.345 \\
(0.244)\end{array}$ & $\begin{array}{l}-0.407 \\
(0.342)\end{array}$ & 0 \\
\hline Graduate school & $\begin{array}{c}-0.344 \\
(0.346)\end{array}$ & $\begin{array}{c}0.014 \\
(0.468)\end{array}$ & 0 \\
\hline \multicolumn{4}{|l|}{ Annual household income } \\
\hline Low income & $\begin{array}{c}11.966 \\
(48.399)\end{array}$ & $\begin{array}{c}-1.139 \\
(1.575)\end{array}$ & 0 \\
\hline Medium income & $\begin{array}{c}12.195 \\
(48.398)\end{array}$ & $\begin{array}{c}-1.501 \\
(1.557)\end{array}$ & 0 \\
\hline High income & $\begin{array}{c}12.136 \\
(48.399)\end{array}$ & $\begin{array}{c}-1.299 \\
(1.555)\end{array}$ & 0 \\
\hline Higher income & $\begin{array}{c}12.479 \\
(48.399)\end{array}$ & $\begin{array}{l}-0.921 \\
(1.547)\end{array}$ & 0 \\
\hline \multicolumn{4}{|l|}{ Purchasing habit } \\
\hline Frequent buyer & $\begin{array}{c}-0.396^{*} \\
(0.205)\end{array}$ & $\begin{array}{c}-0.452 \\
(0.278)\end{array}$ & 0 \\
\hline Occasional buyer & $\begin{array}{c}-0.606^{*} \\
(0.323)\end{array}$ & $\begin{array}{c}0.225 \\
(0.362)\end{array}$ & 0 \\
\hline Number of peaches per purchase & $\begin{array}{l}0.141 * * \\
(0.061)\end{array}$ & $\begin{array}{c}0.109 \\
(0.082)\end{array}$ & 0 \\
\hline Live alone & $\begin{array}{c}-0.276 \\
(0.283)\end{array}$ & $\begin{array}{c}0.216 \\
(0.365)\end{array}$ & 0 \\
\hline $\begin{array}{l}\text { Intercept } \\
\text { share }\end{array}$ & $\begin{array}{r}-11.96 \\
48.8 \%\end{array}$ & $\begin{array}{r}0.607 \\
17.5 \%\end{array}$ & \\
\hline
\end{tabular}

A control variable for the "Neither A or B" option in the scenario questions is also included in the model. *Significant at the $10 \%$ level, $* *$ significant at the $5 \%$ level, and ***significant at the $1 \%$ level.

purchase and had relatively smaller percentages of occasional buyers, indicating they were frequent buyers. Meanwhile, balanced consumers (class 2) had the lowest percentage and search attribute-oriented consumers had the highest percentage of male con- sumers. This finding was consistent with Campbell et al. (2013), who found that male consumers were more likely to be price sensitive.

Willingness-to-pay (WTP) values were calculated and are reported in Table 5. For experience attribute-oriented consumers, the insignificance of price coefficient did not allow for WTP calculation. However, it also indicated the preferences for sweetness and flavor among experience attribute-oriented consumers strongly dominated their choices for peach regardless of the price. For search attribute-oriented consumers, they were willing to pay $\$ 0.13 / \mathrm{lb}$ to increase fruit size from less than 2.75-inch diameter to larger size, followed by the improvement of firmness, external color, and sweetness with WTP values of $\$ 0.12 / \mathrm{lb}, \$ 0.05 / \mathrm{lb}$, and $\$ 0.04 / \mathrm{lb}$, respectively. Search-attribute consumers also discounted the increase in external blemishes by $\$ 0.09 / \mathrm{lb}$, showing their inclination for better search attributes. Lastly, for balanced consumers, the WTP results indicated they preferred an increase in sweetness and a decrease in external blemish, so both search attributes and experience attributes could affect their purchasing decision.

\section{Conclusions and Marketing Implications}

In this paper, we explored U.S. consumers' preference heterogeneity for quality attributes of fresh peaches using a choice experiment with a random sample of 800 U.S. consumers. Based on preference heterogeneity, participants were classified into three groups: experience attribute-oriented consumers, who valued fruit quality; search attribute-oriented consumers, who valued fruit appearance; and balanced consumers, who considered search attributes and experience attributes but who valued each in a balanced way. The balanced consumers and search attribute-oriented consumers were price sensitive, but the experience attributeoriented consumers were not.

Gender was a factor that differentiated groups. Balanced consumers were more likely to be female, followed by experienced attribute-oriented consumers, whereas search attribute-oriented consumers were more likely to be male. Fewer experience attributeoriented consumers had children and showed higher purchase frequency and volume per purchase.

Each stakeholder of the supply chainbreeders, growers, wholesalers, and retailerscould contribute to increasing consumption and hence the sales of fresh peaches. From the perspectives of breeders and growers, achieving quality consistency with sweeter, more intense flavored, and larger peaches is fundamental. Improvements in these attributes not only bring highest price premiums but also attract all three groups of consumers. Meanwhile, minimizing external blemishes is also crucial. This requires growers to use proper techniques in cultivation and harvest and wholesalers and retailers to carefully manage their postharvest handling practices and personnel during transportation, storage, and merchandising.

To target experience attribute-oriented consumers, our findings suggest a key is to create and maintain a favorable consumer experience by providing peach fruit with 
Table 5. Willingness-to-pay estimates for peach attributes across the consumer segments identified by latent class logit model using the U.S. peach consumer survey (sample size: 800 ).

\begin{tabular}{lccc}
\hline & \multicolumn{3}{c}{ Willingness-to-pay $(\$ / \mathrm{lb})$} \\
\cline { 2 - 4 } Attributes & $\begin{array}{c}\text { Class 1: Experience } \\
\text { attribute-oriented Consumers }\end{array}$ & $\begin{array}{c}\text { Class 2: } \\
\text { Balanced consumers }\end{array}$ & $\begin{array}{c}\text { Class 3: Search } \\
\text { attribute-oriented consumers }\end{array}$ \\
\hline External blemishes & - & -0.07 & -0.09 \\
External color & - & - & 0.05 \\
Size & - & - & 0.13 \\
Firmness & - & - & 0.12 \\
Sweetness & - & 0.25 & 0.04 \\
Flavor & - & - & - \\
"-" indicates that either the estimated coefficient for product attributes or price is not statistically \\
significant, and the willingness to pay value is not calculated.
\end{tabular}

a high level of sweetness and intense flavor. Breeding programs should develop cultivars that regularly exceed threshold levels defining superior quality. Such cultivars may confront growers with a trade-off dilemma because genetically high-yielding and large peach cultivars often are deficient in sweetness and flavor components. Retailers could distribute free samples of peaches in stores and target more of the samples to female consumers. In addition, by sourcing products from growers and shippers who reliably provide fruit superior for these two key attributes, wholesalers and retailers could build up a positive reputation for specific origins of production or certain brands, which would become positive signals of desired quality for experience attribute-oriented consumers. Distributing free samples and working with specific growers and shippers may impose a higher cost to retailers. Therefore, this strategy of targeting experience attributeoriented consumers might be more suitable for retailers who are able to charge a higher price for their products, for example, highend, natural food stores such as Whole Foods.

The key attributes to attract search attribute-oriented consumers are appealing appearance and competitive price, in addition to sweetness. Because affordable price would also attract balanced consumers, competitive pricing strategy could capture these two groups at one time. For peach cultivars that could be sold at lower prices, wholesalers and retailers may select larger and firmer peaches to distribute or to display in stores. Conventional stores such as Cub Foods, Kroger, and Safeway and warehouse retailers such as Walmart may be more competitive to target search attribute-oriented consumers and balanced consumers.

Additional advertising tools for retailers appropriate for all three classes could be weekly advertisement brochures and direct mail/e-mail campaigns. Retailers could deliver coupons for fresh peaches to male consumers, who are more likely to be search attribute-oriented consumers and seek affordable prices. Advertising brochures or other activities to keep peaches as a top-of-mind fruit could be used to inform experience attribute-oriented consumers of the arrival of their preferred fresh peaches from certain brands or production origins.

\section{Literature Cited}

Adalja, A., J. Hanson, C. Towe, and E. Tselepidakis. 2015. An examination of consumer willingness to pay for local products. Agr. Resour. Econ. Rev. 44(3):253-274.

Boxall, P.C. and W.L. Adamowicz. 2002. Understanding heterogeneous preferences in random utility models: a latent class approach. Environ. Resour. Econ. 23(4):421-446.

Bruhn, C.M. 1995. Consumer and retailer satisfaction with the quality and size of California 241-256.

Campbell, B.L., R.G. Nelson, R.C. Ebel, W.A. Dozier, J.L. Adrian, and B.R. Hockema. 2004 Fruit quality characteristics that affect consumer preferences for Satsuma mandarins. HortScience 39:1664-1669.

Campbell, B.L., S. Mhlanga, and I. Lesschaeve. 2013. Consumer preferences for peach attributes: Market segmentation analysis and implications for new marketing strategies. Agric. Resour. Econ. Rev. 42(3):518-541.

Cembalo, L., G. Cicia, and T. Del Giudice. 2009. The influence of country of origin on German peaches and nectarines. J. Food Qual. 18(3): consumer preferences for peaches: A latent class choice model, p. 3-6. In European Association of Agricultural Economists; 113 th Seminar, Sept. 2009.

Crisosto, C.H., G.M. Crisosto, and P. Metheney. 2003. Consumer acceptance of 'Brooks' and 'Bing' cherries is mainly dependent on fruit SSC and visual skin color. Postharvest Biol. Technol. 28(1):159-167.

Darby, M.R. and E. Karni. 1973. Free competition and the optimal amount of fraud. J. Law Econ. 6:67-88.

Dobbs, L.M., K.L. Jensen, M.B. Leffew, B.C. English, D.M. Lamber, and C.D. Clark. 2016. Consumer willingness to pay for Tennessee beef. J. Food Distrib. Res. 47(2):38-61.

Economic Research Service (ERS), U.S. Department of Agriculture. 2015. Fruit and tree nut data, peaches, trade tables. 25 Oct. 2018 $<$ http://www.ers.usda.gov/data-products/fruitand-tree-nut-data/data-by-commodity.aspx $>$.

Economic Research Service (ERS), U.S. Department of Agriculture. 2017. Fruit and tree nuts yearbook: Report. 25 Oct. 2018. $<$ http://usda.mannlib.cornell.edu/usda/ers/89022/ 2017/FruitandTreeNutYearbook2017.pdf $>$.

Food and Agricultural Organization of the United Nations (FAO). 2018. Statistical Database Agriculture. 25 Oct. 2018. <http://faostat. fao.org/site/339/default.aspx $>$.

Kontoleon, A. and M. Yabe. 2003. Assessing the impacts of alternative 'opt-out' formats in choice experiment studies: Consumer preferences for genetically modified content and production information in food. J. Agr. Policy Resour. 5(1): 1-43.

Loureiro, M.L., J.J. McCluskey, and R.C. Mittelhammer. 2001. Assessing consumer preferences for organic, eco-labeled, and regular apples. J. Agr. Resour. Econ. 26(2):404-416.

Nelson, P. 1970. Information and consumer behavior. J. Polit. Econ. 78:311-329.

Nelson, P. 1974. Advertising as information. J Polit. Econ. 83:729-754.

Uva, W.F.L., S.R. Cuéllar, and M.L. Cheng. 2004. Consumer preferences and marketing opportunities for premium" tree-ripened peaches" in New York State. Department of Applied Economics and Management, College of Agriculture and Life Sciences, Cornell University, Ithaca, NY.

Uva, W.F.L. and M.L. Cheng. 2005. Consumer willingness to pay and marketing opportunities for "quality guaranteed tree-ripened peaches" in New York State. J. Food Distrib. Res. 36(1): 177-184.

van der Pol, M. and M. Ryan. 1996. Using conjoint analysis to establish consumer preferences for fruit and vegetables. Brit. Food J. 98(8):5-12. 